\title{
Analytical and artificial neural network models to estimate the discharge coefficient for ogee spillway
}

\author{
Alpaslan Yarar ${ }^{1, *}$ \\ ${ }^{1}$ Selcuk University, Engineering Faculty, Civil Engineering Department, Hydraulics Division, 42031 Konya, Turkey
}

\begin{abstract}
In this study, analytical and Artificial Neural Network (ANN) model were used for determine the discharge coefficient of Ogee Spillways. For this aim, discharge coefficients of 11 different heads were calculated by using a test flume having $7.5 \mathrm{~cm}$ width, $15 \mathrm{~cm}$ depth and $5 \mathrm{~m}$ length, in the laboratory. Discharge coefficients were also computed by the formula for the same heads measured in the laboratory to investigate the accuracy of experimental setup. An ANN model was set by using the experimental results in order to estimate the discharge coefficient. Then, the performance of the ANN model was investigated. As the result, the coefficient of determination between ANN model and experimental setup is found $\mathrm{R}^{2}=0.98$. ANN model is show a good consistency with experimental results.
\end{abstract}

\section{Introduction}

Spillways are used to hold water at a certain level in reservoir besides to store water for different aims, such as energy, irrigation, flood control, etc. Ogee-shaped spillways let excessive water in reservoir pass to downstream. The ideal form of the spillway recommended by The United States Bureau of Reclamation (USBR) [1] is seen in Fig. 1.

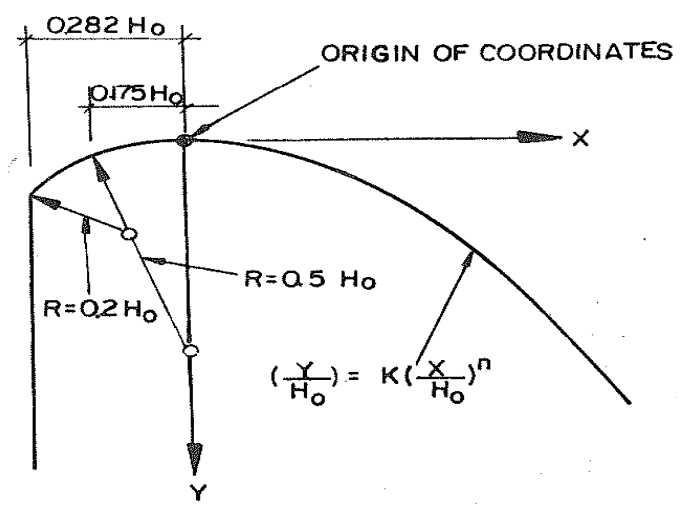

Fig. 1. Standard crest profile of an overflow spillway [1]. Eq.1.

The downstream of the spillway can be defined by

$\frac{Y}{H_{0}}=K\left(\frac{X}{H_{0}}\right)^{n}$

$\mathrm{K}$ and $\mathrm{n}$ are constant, depend on the upstream inclination and the velocity and $\mathrm{H}_{0}$ is the design head.
The discharge over the spillway can be calculated by Eq. 2.

$Q=C L H^{3 / 2}$

Q $\left(\mathrm{m}^{3} / \mathrm{s}\right)$ is the discharge, $\mathrm{C}$ is the discharge coefficient, $L(m)$ is the length of the crest and $H(m)$ is the head over the crest.

Spillways are rarely operated with their design head since the design head corresponds to very large return periods having relatively small risks. Therefore, the discharge coefficient for an existing total operated head should be determined by the Fig. 2 [2].

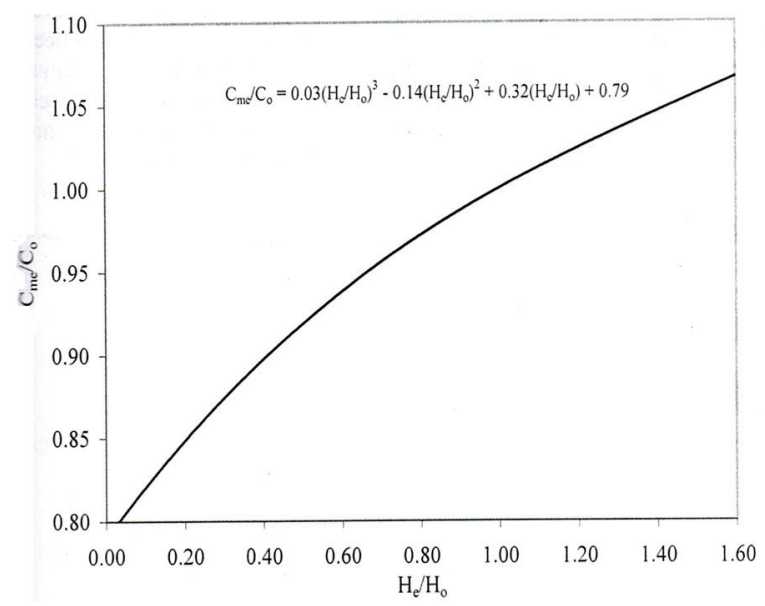

Fig. 2. Discharge Coefficients for varying heads.

Many researchers have studied for numerical and experimental studies on spillways [3-7]. And ANN

*Corresponding author: ayarar@selcuk.edu.tr 
model have also used for studies on spillways. Azamathulla et. al. [8], studied for scour depth prediction for ski-jump type of spillways. They also used some traditional methods. Their study showed that the traditional equation-based methods of predicting design scour downstream of a ski-jump bucked could better be replaced by one of the soft computing schemes [8]. Salmasi and Özger [9], investigated the applicability and accuracy of the neuro-fuzzy approach in estimating the proper values of energy dissipation of skimming flow regime over stepped spillways. They were also developed multi regression equations. They found that neuro-fuzzy model is more successful than regression equations [9].

In this study, it was aimed that to investigate the capability of ANN model to estimate the discharge coefficient for Ogee spillway.

\section{Materials and Methods}

In this study, an experimental setup containing a simple flume which was made plexiglass and having $7.5 \mathrm{~cm}$ width, $15 \mathrm{~cm}$ depth and $5 \mathrm{~m}$ length, was used in order to calculate discharge passing over ogee-shaped spillway for different heads (Fig. 3). The flume had closed loop water system and the flow to the flume was supplied from constant head water tank and the flow discharge was regulated by a valve. That the transparent flume also enables to see the flow conditions. Flow depth measured with a measurement device holded along the flume to an accuracy of $\pm 1 \mathrm{~mm}$.

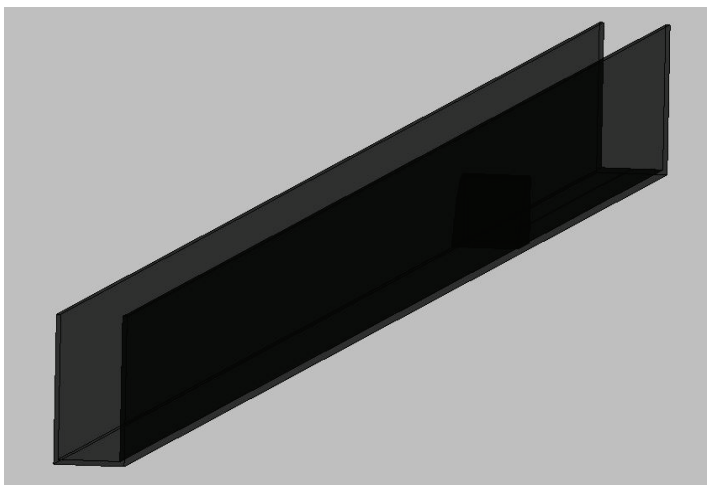

Fig. 3. General view of the flume used in the study.

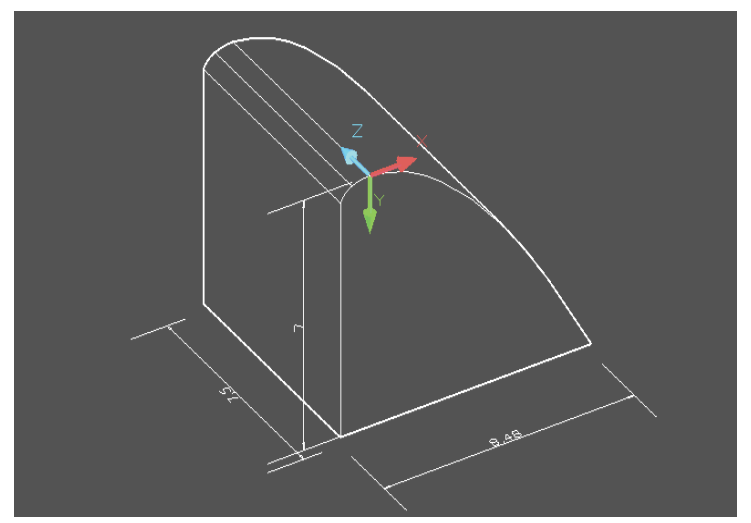

Fig. 4. Ogee spillway model.
A tank, made by smooth plastic which has $63 \times 67 \times$ $72 \mathrm{~cm}$ dimensions, was used to measure the discharge. An ogee spillway model was modeled by Eq. 1 according to USBR type and manufactured with steel material to use in the experiments (Fig. 4).

\section{Artificial Neural Networks}

The composition of ANN is inspired from biological neural networks. A neuron is one of the basic components of neural networks. It can vary in terms of size and shape, according to its function and mission in neural systems [10].

The system consisting of three layers, an input layer, an hidden layer and an output layer, named Multi Layer Perceptron (MLP) (Fig. 5).

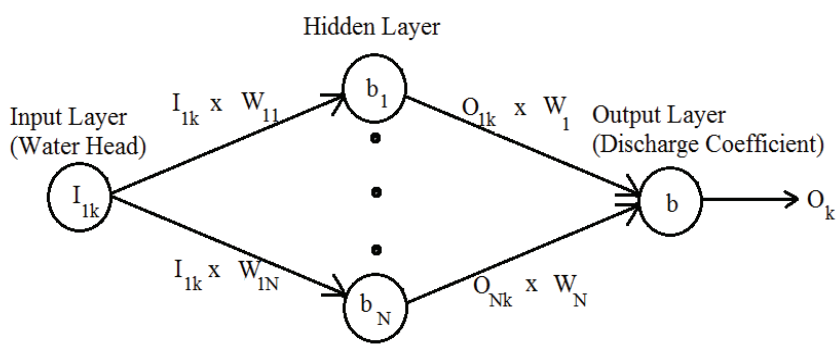

Fig. 5. A structure of Multilayer Perceptron.

The mathematical expression of a three-layer feed forward ANN for prediction is

$$
\begin{gathered}
\mathrm{O}_{\mathrm{jk}}=\mathrm{f}_{1}\left(\mathrm{~b}_{\mathrm{j}}+\sum_{\mathrm{i}} \mathrm{W}_{\mathrm{ij}} \mathrm{I}_{\mathrm{ik}}\right) \\
\mathrm{O}_{\mathrm{k}}=\mathrm{b}+\sum_{\mathrm{i}} \mathrm{W}_{\mathrm{j}} \mathrm{O}_{\mathrm{jk}}
\end{gathered}
$$

where:

$f_{1}$ is the activation function for the hidden layer, $I_{\text {ik }}$ is the $i_{\text {th }}$ input for the $k_{\text {th }}$ sample point,

$\mathrm{O}_{\mathrm{jk}}$ is the output of $\mathrm{j}_{\mathrm{th}}$ node of the hidden layer,

$\mathrm{W}_{\mathrm{ij}}$ and $\mathrm{W}_{\mathrm{j}}$ are the weights that control the strength of connections between layers,

$b_{j}$ and $b$ are the biases that are used to adjust the mean value for the hidden layer and the output layer, respectively [11]

\section{Results and discussion}

The flow depths over the spillway were measured for different discharge. The discharges were determined by the tank for each water heads to calculate the discharge coefficients. This process was done with holding time until filling certain volume (Fig. 6).

Discharge coefficients were calculated by Eq. 2 using the water heads.

Then the discharge coefficients obtained from both experimental and analytical results were compared with each other. 

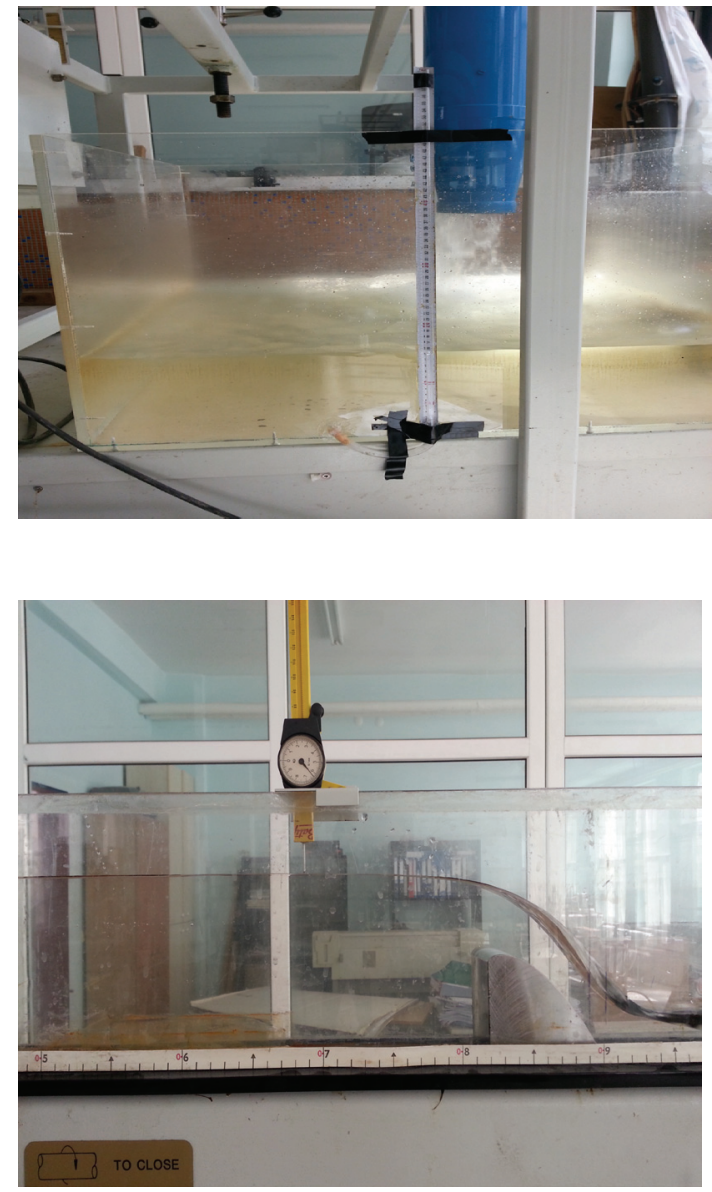

Fig. 6. Water depth and discharge measurement points on the experimental set up.

Discharge coefficients were calculated by Eq. 2 using the water heads. Then the discharge coefficients obtained from both experimental and analytical results were compared with each other. Measured water heads and corresponding discharge coefficients for both experimental and analytical studies were given in Fig. 7.

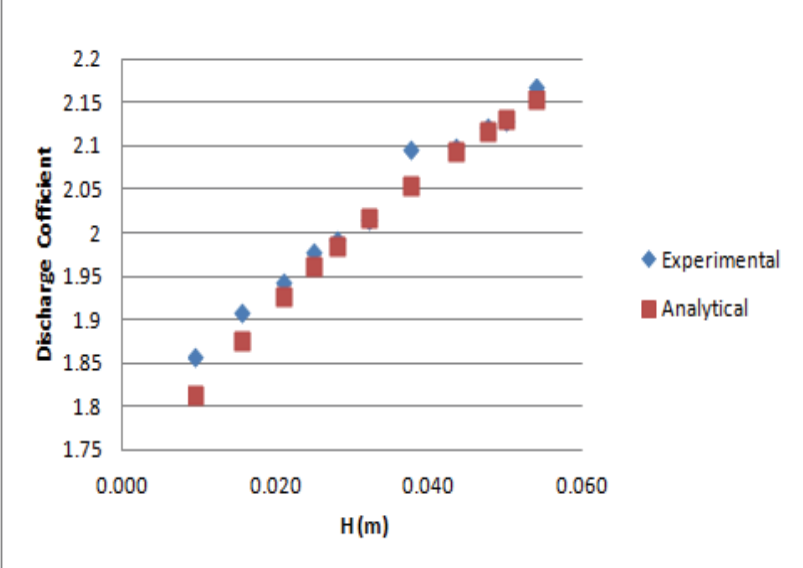

Fig. 7. Comparison of the experimental and analytical results.

Experimental results were used for ANN modeling. 6 data set of the 11 data set were used for training and remaining 5 data set were used for testing. Feed forward back propagation ANN model and Scaled Conjugate Gradiant (SCG) algorithm were used for modeling.
Three layered ANN formed with 1 input layer 1 hidden layer and 1 output layer was used in ANN model. The relationship between ANN results and experimental results is shown in Fig 8.

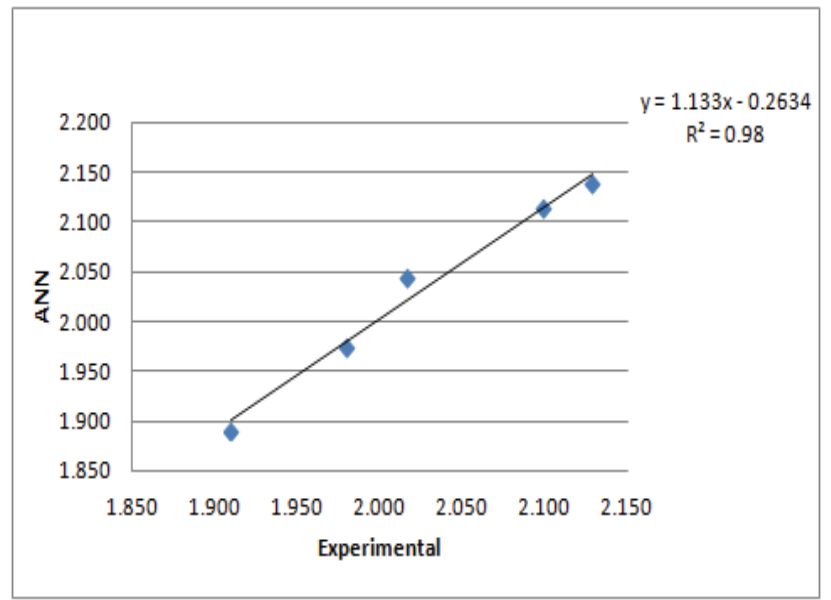

Fig. 8. Relationship between the results of experimental and ANN test.

\section{Conclusions}

Hydraulic design of a spillway is one of the most studied subjects in hydraulic engineering. Properly designed spillways will be able to pass flood flows efficiently and safely to downstream of dams. So, determining the discharges correctly becomes important for the water structures. To determine the discharges depends on to determine the discharge coefficients. In recent years, artificial intelligence methods based on learning from examples have been widely applied in hydraulic studies. In this study, it was aimed to investigate the ANN performance on determining the discharge coefficients. For this purpose both experimental and analytical studies were done. It was seen that ANN model produced very successful results. Overall, the studies presented in this paper showed us that ANN model can be an alternative method to determine the discharge coefficients. Using ANN model, we can determine the proper coefficients quickly, without using the graphs and the equations.

\section{References}

1. USBR, 1987, Design of small dams, Third Edition, Washington: Water Resources Technical Publication

2. A. M. Yanmaz, Applied water resources engineering (METU Press, 2001).

3. B.M. Savage, M.C. Johnson, J. Hydraul. Eng. ASCE; 127, 8, 641-9 (2001)

4. C. Song, F. Zhou. J Hydraul Eng, ASCE, 125, 9, 959-67 (1999)

5. J.M. Sanchez, J. Pomares, J. Dolz, Proceedings, International Workshop on Hydraulics of Stepped Spillways, Zurich, Switzerland, 2000.

6. B. Dargahi, J. Hydraul. Eng, ASCE, 132, 98, 99-907 (2006).

7. B. M. Savage, M.C. Johnson, Flow over ogee spillway, J. Hydraul. Eng. 127, 8640-649 (2001) 
8. H. Azamathulla, M.C. Deo, P.B. Deolalikar, Advances in Engineering Software 39, 689-698 (2008)

9. F. Salmasi, M. Özger. Arab. J. Sci. Eng. 39, 60996108 (2014)

10. A. Dorum, A. Yarar, M.F. Sevimli, M. Onüçyildiz, Expert Syst .Appl. 37, 6587-6593 (2010)

11. N. Chitsazan, A. A. Nadiri, F. T. C. Tsai. J. Hydrol. 528, 52-62 (2015) 